\title{
A Rare Case of a Huge Retroperitoneal Tuberculous Cystic Mass in an 18 Year Old Ethiopian Female
}

\section{Dr Nasib Al Shibli*}

Senior Registrar in General Surgery,

FACS,FRCSI, MRCSEng,

Arab Board/Syrian Board in G.S

https://www.facs.org/profile/55967876

https://orcid.org/0000-0003-3291-2656

Prince Mutaib Bin AbdulAziz Hospital, Sakaka AlJouf, Saudi Arabia

*Corresponding Author: Dr Nasib Al Shibli, FACS. E-mail: nasib_kais@yahoo.com
Received: October 07, 2021

Published: December 09, 2021

(C) All rights are reserved by Dr Nasib Al

Shibli.

\begin{abstract}
Retro peritoneal tuberculosis (TB) a typical mycobacterium infection that is difficult to diagnose as it mimics other gastro-intestinal infections. Mis-diagnosing may result in delayed therapy which may lead to further complication.

An 18-year-old young female Ethiopian admitted in Prince Mutaib Bin Abdul-Aziz hospital. Her symptoms were prolonged lowgrade fever (more than 2 months) with insidious vague abdominal pain. She doesn't have previous surgical interference or no clear history of TB.

CT of abdomen was performed and it has shown a huge retroperitoneal cystic mass form left duodenum down to left iliac fossa. After the CT results a surgical drainage of iliac region and the aspiration cytology of straw-coloured_lluid shown the presence of epithelial granulomas, muscle bundles, fibro-adipose tissue, inflammation similar to Mycobacterium tuberculosis infection.
\end{abstract}

Keywords: Mycobacterium tuberculosis; Retro-peritoneal Tuberculosis; Abdominal Pain; Ct-scan; Surgical Drainage

\section{Introduction}

Now a days, the world is facing high mortality because of an infectious disease. The deaths caused by Tuberculosis has ranked 10 around the world. A quarter of the world population were affected by Mycobacterium tuberculosis [1]. Tuberculosis (TB) is contagious and airborne disease. TB was one of the top TEN causes of death worldwide in 2018; as mentioned in GLOBAL TUBERCULOSIS (Report 2019). Tuberculosis infects mostly the pulmonary region. Some studies shows that the tuberculosis can infect other regions and is called EXTRA PULMONARY tuberculosis, that include oral tuberculosis, esophageal tuberculosis, gastro intestinal tuberculosis (GITB), anal tuberculosis, peritoneal tuberculosis, Hepatobiliary tuberculosis and pancreatic tuberculosis [2]. The infection spreads to GI tract by hematogenous spread during or after active pulmonary TB. Malnutrition and supplement of contaminated food, engulfing of infected sputum may results in Extrapulmonary TB. The GITB is mostly observed in iliac region of stomach. The infection to the GI tract causes the inflammation of mucosa leading to ulceration and necrosis. This condition is seen in the other regions of GI tract once it is infected with bacterium [3].

\section{Case Report}

An eighteen (18) years old young female Ethiopian was admitted in surgery ward of Prince Mutaib Bin Abdul-Aziz hospital in May 2014, she had history of prolonged low-grade fever (more than 2 months), insidious vague abdominal pain, no clear history of T.B, and no history of previous surgical interference.

Physical Examination, there was tenderness in left flank and lower abdomen. 
Laboratory findings revealed high ESR, CRP, and $\mathrm{WBC}=18,000$ (80\% Neutrophilia and 11\% lymphocytes), HB 10.2 G/dl, Platelets 350,000/UL. Virology profile as regard HIV and Hepatitis C AB Were negative. Radiological investigations: Chest $\mathrm{x}$ ray unremarkable, CT abdomen (Figure 1 ) revealed a huge retroperitoneal cystic mass $16 \mathrm{~cm}$ x $11 \mathrm{~cm}$ extending from the duodenum above down to left iliac fossa, no spinal involvement. Percutaneous needle aspiration revealed straw color, thick fluid but was not sufficient for cytopathological evaluation and contains no growth.

Open surgical drainage through left iliac fossa was decided. Retroperitoneal Approach, drifting the peritoneal cavity medially; in gush about 1.5 litres of straw-coloured thick fluid with pus was evacuated then retroperitoneal space was irrigated adequately with copious amounts of warm saline mixed with 3rd generation Cephalosporin.
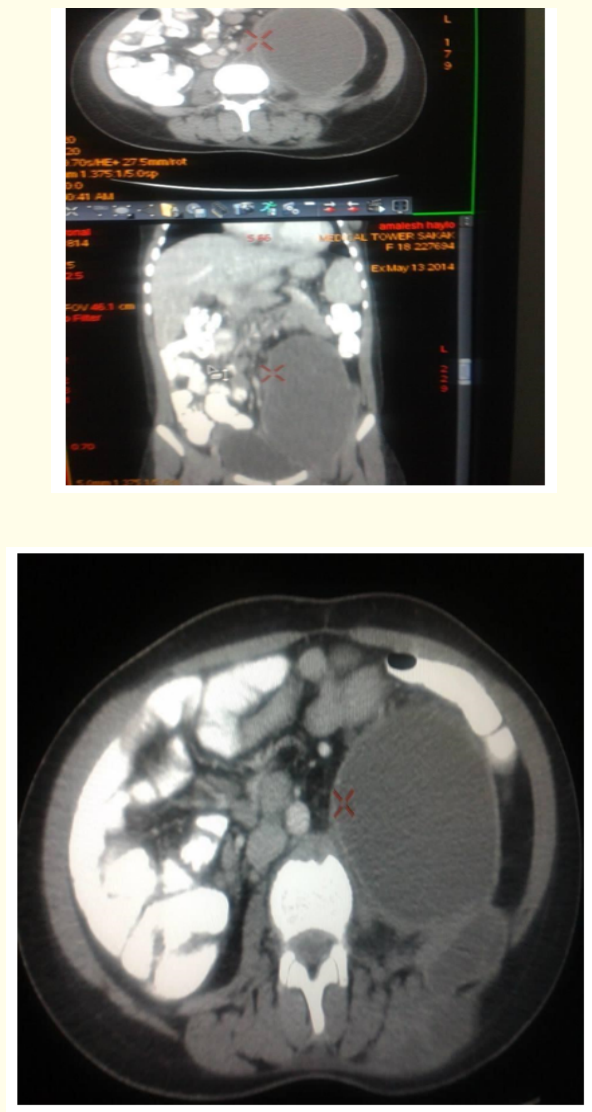

Figure 1: Retroperitoneal collection: rare localization of Tuberculosis.
Postoperative bacteriological swab was polymicrobial (E. coli, Staph. Aureus).and Acid-Fast Bacilli test was positive.

\section{Diagnosis}

Pathological report revealed muscle bundles, fibro adipose tissue in degenerated areas, heavy mixed inflammation, haemorrhage. Multiple granulomas were identified formed of epithelioid cells, lymphocytes, plasma cells with prominent multinucleated giant cells Langerhans type, areas of acute suppurative inflammation; picture is in favour of tuberculous inflammation.
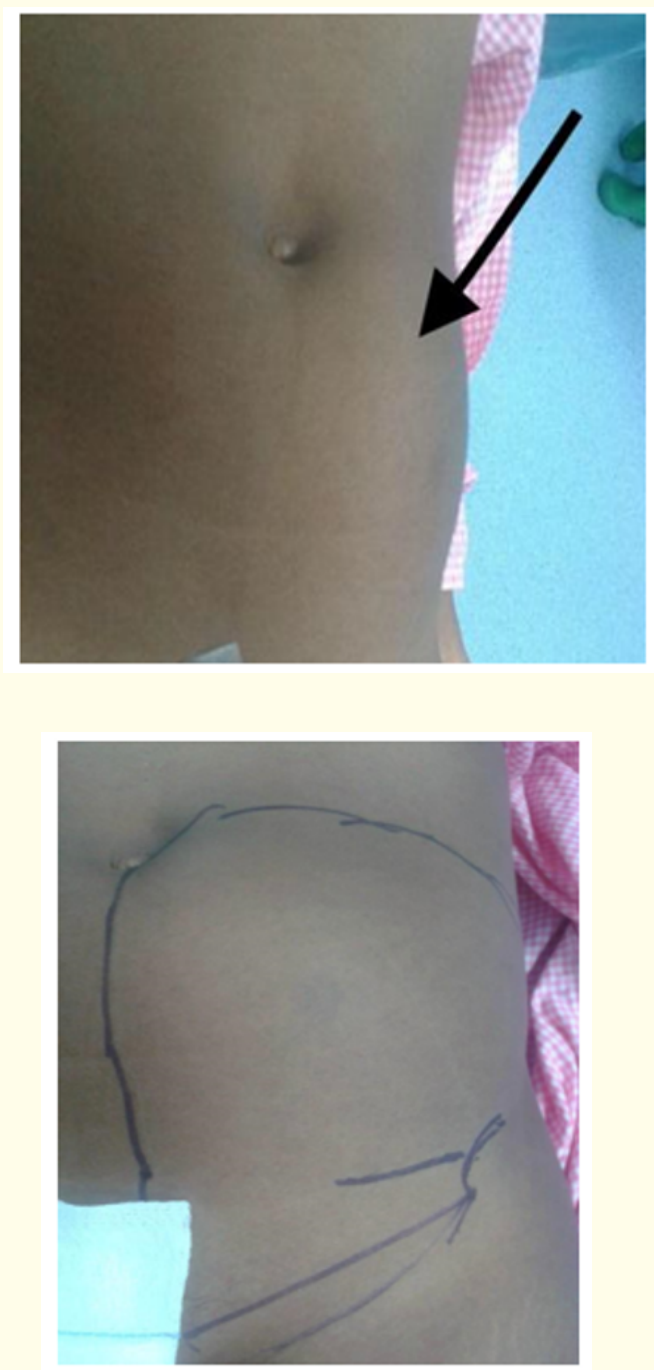

Figure 2: Showing inflammation/tenderness in left flank and lower abdomen region. 


\section{Treatment}

From the pathological finding a full course of anti-tuberculosis (4 drug therapy) for the next 6 months was started for the patient. Initially for the first two months of INH (Isoniazid), rifampicin, pyrazinamide and ethambutol were prescribed to the patient. After completion of the 4-drug therapy for two months, isoniazid and rifampicin alone were prescribed further for 4 months.

Throughout the treatment period, a frequent ultrasound was performed to determine that the prescribed drugs were effective in controlling the infection.

\section{Discussion}

The GI TB is frequently seen in inhabitants with subordinate socioeconomic position. The malnutrition is associated in infection and also with human immunodeficiency virus (HIV) infection and acquired immunodeficiency syndrome.

TB coinfections are the leading cause of death in patients with HIV/AIDs [4].

GITB is difficult to diagnose as the symptoms are non-specific. Because the clinical and radiological results were similar to other diseases like that of Crohn's disease, malignancy, amoebiasis, and Yersinia infection.

In certain patients it takes an elongated time to make an accurate diagnosis of GITB in clinical practice [5]. The histopathological diagnosis of GITB primarily depends on identification of epithelioid cell granulomas (ECGs) with necrosis. Yet, in the absence of caseating granulomas, it becomes difficult to discriminate it from other inflammatory and necrotic granulomatous lesions $[6,7]$.

In our study CT scan on abdomen helped in identifying the mass formation in abdomen region (Figure 4). Followed by surgical drainage of the mass; Post operative pathological studies has resulted in presence of muscle bundles, fibro adipose tissue, inflammation. The microscopical examination revealed multiple granulomas derived of epithelial cells, histocytes, lymphocytes and plasma cells with multinucleated giant cells of inflammation that are similar in tuberculosis infection.

Base on the results obtained the patient was treated for 6 months with anti-tuberculosis medication. The patient has shown response to the treatment.

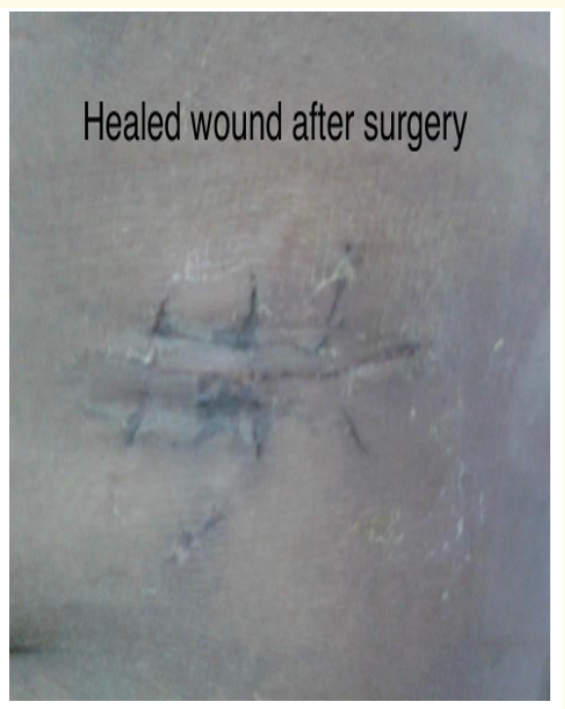

Figure 3: Representing wound healing after the surgical drainage.

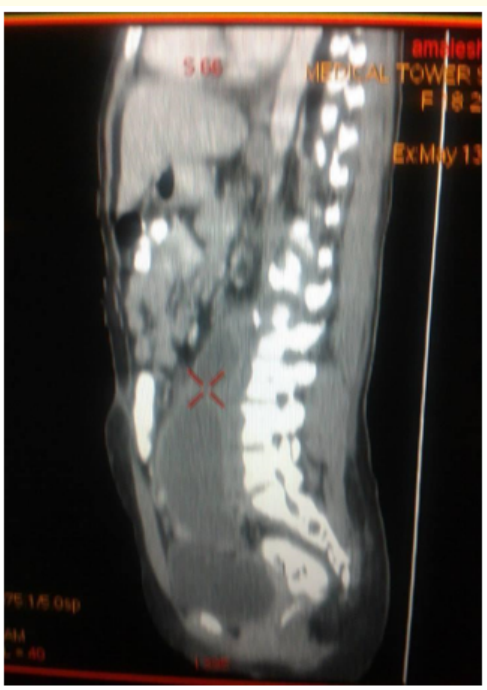

Figure 4: CT-abdomen sagittal view showing abdominal mass.

\section{Conclusion}

This case report shows the complication in diagnosing the infection of Mycobacterium tuberculosis in abdominal region. The CT-scan of the abdomen region showing retro-peritoneal cystic mass. Surgical drainage was performed to drain the fluid mass. 
The aspiration cytology of fluid showing inflammation and epithelial multi-granulomas shows the infection and treatment with Anti-tubercular therapy resulted in patient recovery. Here in this report early diagnosis and early treatment of the patient increases the clinical cure as the tuberculosis is curable and preventable if diagnosed earlier.

\section{References}

1. Haluk Eraksoy MD. "Gastrointestinal and Abdominal Tuberculosis". Gastroenterology Clinics of North America 50 (2021) 241-360.

2. Malikowski T., et al. "Tuberculosis of the gastrointestinal tract and associated viscera". Journal of Clinical Tuberculosis and Other Mycobacterial Diseases 12 (2018): 1-8.

3. Raja Chandra Chakinala., et al. "Gastrointestinal Tuberculosis Presenting as Malnutrition and Distal Colonic Bowel Obstruction". Case Reports in Gastrointestinal Medicine (2018): 3.

4. Raja Chandra Chakinala and Akshay M Khatri. “Gastrointestinal Tuberculosis" (2021).

5. Hulnick DH., et al. "Abdominal tuberculosis: CT evaluation". Radiology 157 (1985): 199-204.

6. Alvares JF., et al. "Clinical, colonoscopic and histological profile of colonic tuberculosis in a tertiary hospital". Endoscopy 37 (2005): 351-356.

7. Patel N., et al. "Gastrointestinal luminal tuberculosis: Establishing the diagnosis". Journal of Gastroenterology and Hepatology 19 (2004): 1240-1246.

\section{Assets from publication with us}

- Prompt Acknowledgement after receiving the article

- Thorough Double blinded peer review

- Rapid Publication

- Issue of Publication Certificate

- High visibility of your Published work

Website: www.actascientific.com/

Submit Article: www.actascientific.com/submission.php

Email us: editor@actascientific.com

Contact us: +919182824667 